\title{
OS PARÂMETROS CURRICULARES NACIONAIS DO ENSINO MÉDIO: A PREPARAÇÃO PARA O MUNDO DO TRABALHO PRECÁRIO*
}

\author{
Patrícia Regina Piovezan \\ da Universidade Estadual Paulista (UNESP); \\ Candido Giraldez Vieitez \\ da Universidade Estadual Paulista (UNESP).
}

Resumo: O objetivo deste artigo é apresentar de que forma a categoria trabalho é abordada nos Parâmetros Curriculares Nacionais do Ensino Médio (PCNEM), visto ser essa categoria a base principal para a formulação da reforma curricular desse nível de ensino. Nesse documento, há dois eixos centrais: o trabalho e a cidadania. Porém, a cidadania é agregada e subordinada às novas exigências do mundo do trabalho que, de acordo com o documento, foi constituído após os anos 1970. Segundo os autores dos PCN do ensino médio, a sociedade contemporânea sofreu duas grandes transformações nessa década - a revolução tecnológica e a do conhecimento - que deram origem às novas exigências do processo produtivo, do mercado de trabalho e das relações sociais. A partir dessas justificativas do MEC para a reforma do ensino médio brasileiro, nosso objetivo, neste artigo, é verificar de que forma a categoria trabalho é conceituada no documento, como a organização curricular do ensino médio se adaptou às novas tendências e quais são essas novas exigências do mundo do trabalho a que o documento pretende se adaptar. Para essa análise, utilizamos as categorias: trabalho, trabalho estranhado e a precarização do trabalho.

Palavras-chave: Parâmetros Curriculares Nacionais do Ensino Médio. Trabalho. Cidadania. Reestruturação produtiva. Precarização do trabalho.

\footnotetext{
* Artigo recebido em 05/08/2010 e aprovado em 11/04/2012.
} 
INTRODUÇÃO

A década de 1970 foi o marco para o início da reestruturação das relações de trabalho no processo produtivo vigente e da reorganização política e econômica em alguns países de economias centrais, como os Estados Unidos e a Inglaterra. A instauração de um novo conjunto de relações econômicas se sustentava na reformulação dos processos de produção das fábricas e dos demais setores, que aos poucos se incorporaram à organização do método de produção toyotista; no abandono das políticas do "estado de bem-estar social" pelas políticas neoliberais, e no aumento das aplicações no mercado de ações (financeirização do capital) que substituía, cada vez mais, os investimentos na produção industrial propriamente dita.

Esse novo quadro de relações políticas e econômicas expandiuse pelo mundo nas décadas de 1980 e 1990, inicialmente nos países de capitalismo avançado e, após o fim da União das Repúblicas Socialistas Soviéticas (URSS), em 1991, nos países que haviam vivenciado a experiência socialista.

Na América Latina, as décadas de 1970 e 1980 foram marcadas pelo domínio de ditaduras militares que tentavam afastar o avanço do perigo vermelho e preparar os países afetados - tais como Chile, Brasil, Argentina, Equador etc. - para a expansão dos investimentos das grandes corporações. Apesar de o Chile ter sido o primeiro país no mundo a ter experimentado as propostas neoliberais, essa nova organização política apenas tornou-se dominante na maior parte das economias centrais e nos países da América Latina a partir da década de 1990.

Para consolidar, no setor educacional, as novas propostas das relações de trabalho do modelo toyotista - que, segundo o discurso dos ideólogos burgueses, tem a função de vincular o conhecimento destinado para o educando com as necessidades do mundo do trabalho -, o Banco Mundial e a Unesco publicaram o documento Educação: um tesouro a descobrir; uma proposta norteadora, especialmente para os países em desenvolvimento, para a implantação das novas aprendizagens em consonância com as exigências da reestruturação produtiva.

No Brasil, esse documento foi publicado em 1996 e utilizado para fundamentar a formulação da nova Lei de Diretrizes e Bases da Educação Nacional, dos Parâmetros Curriculares Nacionais do Ensino Fundamental e Médio etc.. Entre outros objetivos, buscamos analisar, neste artigo, de que forma o Relatório da Unesco, em parceria com o Banco Mundial, interferiu na organização dos Parâmetros Curriculares Nacionais do Ensino Médio, na definição do conceito de trabalho proposto pelos autores dos PCN do Ensino 
Médio, e procuramos definir qual a função da categoria trabalho nessa etapa da educação básica.

Para tanto, neste ensaio, realizamos uma pesquisa bibliográfica sobre a principal categoria que organiza a nova proposta curricular para o ensino médio: o trabalho. Assim, fundamentamos a análise dessa categoria na literatura que acumula os conhecimentos sobre os conceitos de trabalho assalariado, reestruturação produtiva e precarização do trabalho.

Com foco na pesquisa documental, contemplamos a análise dos documentos que norteiam a educação nacional, entre eles, a Lei de Diretrizes e Bases n. 9.394/96, os Parâmetros Curriculares Nacionais do Ensino Médio e o Relatório da Unesco (Educação: um tesouro a descobrir) que, apesar de ter sido desenvolvido por organizações internacionais, oferece diversos conceitos que fundamentam os documentos nacionais.

Para interpretar a realidade da educação média e o mercado de trabalho atual no Brasil, principalmente a inserção dos jovens, utilizamos dados do Instituto de Pesquisa Econômica Aplicada (IPEA).

\section{A REFORMA DA EDUCAÇÃO BRASILEIRA NA DÉCADA DE 1990 E REESTRUTURAÇÃO PRODUTIVA}

Após 25 anos sem realizar uma reforma na educação nacional, tendo sido a última lei sancionada durante o regime militar em 1971 (LDB n. 5.692), o governo do presidente Fernando Henrique Cardoso, em 1996, aprovou a nova Lei de Diretrizes e Bases da Educação Nacional, n. 9.394, que regulamenta a criação de novos parâmetros educacionais para todos os níveis e modalidades do ensino. Para além das boas intenções do governo desse período com os problemas no campo educacional do país, a reforma da educação, na década de 1990, foi necessária para atender aos direitos fundamentais de acesso à educação básica (garantidos na Constituição Federal de 1988) e, com mais vigor, atender aos interesses de um novo processo produtivo, o toyotista. ${ }^{1}$ Esse, em formação no Brasil desde os anos 1980, foi estimulado, durante a era Collor, pela implantação de políticas econômicas para que as empresas promovessem maior competitividade e aprimoramento tecnológico, com vista a inseri-las no circuito da concorrência internacional.

Na década de 1970, a Lei de Diretrizes e Bases privilegiava o ensino de habilitações profissionais na grade curricular do ensino secundário, devido às vigentes necessidades nacionais de expansão na produção de bens de consumo duráveis (automóveis, eletrodomésticos etc.). O"milagre econômico" - como ficou conhecido o período de expansão industrial brasileira, de 1968 a 1973 - necessitava uma mão de obra preparada para o processo de produção 
taylorista-fordista, ${ }^{2}$ o qual exigia dos trabalhadores formação profissional e conhecimentos específicos para operar determinadas máquinas. Dessa forma, o governo da época realizou as reformas indispensáveis na educação para atender às exigências da produção naquele momento, ou seja, a profissionalização das forças de trabalho para agregar valor, na proporção que a indústria fordista determinava.

Em 1990, quando a nova LDB foi sancionada, o objetivo da educação continuava a almejar a aproximação da prática educativa à prática laboral, porém as necessidades produtivas e financeiras eram outras. Nessa década, o Brasil estava passando pela expansão de um novo processo produtivo que invadia a produção industrial e de serviços: o toyotismo. A economia e a política internacional dos países centrais haviam passado, recentemente, nas décadas de 1970 e 1980, por transformações que deram origem à expansão de novas relações: a mundialização do capital e a implantação das políticas neoliberais. Essas transformações incluíram o Brasil, nos anos 1990, na nova era da financeirização do capital e dos processos produtivos da empresa enxuta.

A década de 1970 havia sido marcada pela crise do petróleo, o fim do acordo de Bretton Woods (que regulamentava a política econômica internacional e a taxa de câmbio fixa), o fim das políticas de bem-estar social nos países centrais; uma crise de superprodução e do sonho de alcançar o padrão de consumo americano. Esses fatores deram início ao processo de mais uma crise do capital que, mergulhado em suas próprias contradições, deflagrou um colapso ambiental da educação, da instituição familiar, da religião e, principalmente, do próprio capital. Esse, na ânsia por produzir lucros, entra em crise ao gerar uma produtividade de mercadorias muito além do que seria presumível o mercado consumir (MÉSZÁROS, 2009, p. 54-55).

A partir dessa conjuntura, a produção de valor necessitou criar novas alternativas, já que a produtividade excessiva, no perfil da empresa fordista, havia entrado em colapso. Assim, utilizando o método de produção que a empresa Toyota desenvolvia no Japão desde os anos 1950 - produção conforme a demanda, menor número de trabalhadores operando diversas máquinas, sistema just-in-time e kanban, fornecedores subordinados aos interesses da montadora etc. -, empresas do mundo todo e de diversos setores reestruturaram sua produção, seguindo, conforme suas necessidades particulares, o método toyotista (empresa enxuta).

Esse método, além de ajustar a produção de acordo com a demanda do consumo, era adequado para outras estratégias do capital na criação de valor; ou seja, a utilização das descobertas da III Revolução Tecnológica - por meio da tecnologia, investia-se na substituição de trabalhadores (o trabalho vivo) por máquinas e robôs (trabalho morto) - e a mundialização do capital 
ou globalização. Essa, de acordo com Alves (1999, p. 50), "se caracteriza, principalmente, pela predominância do capital financeiro no processo de acumulação capitalista em detrimento das demais frações do capital - a industrial e a comercial".

Esse novo quadro na economia mundial, que se ampliava dos países centrais em direção aos países periféricos, provocou, também, a expansão da estratégia política mais adequada às novas exigências do capital financeiro, as políticas neoliberais. As medidas políticas desse novo Estado, contrário ao bem-estar social, permitiam uma taxa de câmbio flutuante, a privatização de empresas estatais, a queda nos investimentos para as políticas públicas, a abertura para novos investimentos do capital estrangeiro, a flexibilização dos direitos trabalhistas etc.; isso é, estratégias que facilitavam a inserção e expansão do capital financeiro por países do mundo todo.

Durante o governo do presidente Fernando Henrique Cardoso, as políticas neoliberais foram implantadas no Brasil para tornar o país um atrativo para os investimentos dos capitais internacionais. Seguindo a agenda de ajuste político e econômico do Banco Mundial e do Fundo Monetário Internacional (FMI), a educação nacional (que entre 1990-1998 recebeu um montante em torno de U\$850 milhões) também participou dos novos acordos que o governo de Fernando Henrique Cardoso assinou com essas instituições internacionais.

A Lei de Diretrizes e Bases da Educação Nacional (1996) e os documentos que a sucederam - os Parâmetros Curriculares Nacionais do Ensino Fundamental (1997); as Diretrizes Curriculares para o Ensino Infantil (1998); e os Parâmetros Curriculares Nacionais do Ensino Médio (1999); este último sendo o documento de análise deste artigo - possuem em comum, em maior ou menor magnitude, a influência do documento desenvolvido pelo Banco Mundial em parceria com a Unesco: Educação: um tesouro a descobrir. Sua finalidade é divulgar, especialmente para os países em desenvolvimento, as novas tendências para uma educação mundializada no século XXI.

É a partir dessa breve contextualização política e econômica que, na próxima seção, apresentaremos quais são as novas exigências indicadas pelo Relatório da Unesco à educação nacional e, principalmente, ao ensino médio que, por ser a última fase da etapa básica, assume o caráter de preparação para a vida produtiva e social do educando. A proposta em pesquisar os PCN do ensino médio está relacionada com a relevância que a categoria trabalho é abordada pelos autores do documento, enquanto eixo norteador para a reforma curricular, e pelo relevante índice de desemprego entre os jovens brasileiros, observado nas pesquisas recentes. 
ENSINO MÉDIO E A PREPARAÇÃO PARA O TRABALHO

A organização curricular dos PCN do ensino médio adota, como fundamentação teórica para esse nível de ensino, os princípios sancionados, em 1996, na Lei de Diretrizes e Bases da Educação Nacional. Nessa fase do ensino, o governo é bastante pragmático por associar, sem entraves, o vínculo indispensável entre a educação e o trabalho. No artigo 35, essa estreita relação é apresentada a partir das seguintes finalidades:

I - a consolidação e o aprofundamento dos conhecimentos adquiridos no ensino fundamental, possibilitando o prosseguimento de estudos;

II - a preparação básica para o trabalho e a cidadania do educando, para continuar aprendendo, de modo a ser capaz de se adaptar com flexibilidade a novas condições de ocupação ou aperfeiçoamento posteriores;

III - o aprimoramento do educando como pessoa humana, incluindo a formação ética e o desenvolvimento da autonomia intelectual e do pensamento crítico;

IV - a compreensão dos fundamentos científico-tecnológicos dos processos produtivos, relacionando a teoria com a prática, no ensino de cada disciplina. (BRASIL, 1999, p. 33)

Esses princípios, destacados pelos elaboradores da LDB, almejam atender às necessidades da educação no início da década de 1990. Além da pretensa preparação da mão de obra nacional para um mercado de trabalho em expansão devido aos novos investimentos de grandes corporações, atendiam às indicações do Relatório da Unesco (Educação: um tesouro a descobrir) que enfatiza uma formação adequada às novas exigências do mercado de trabalho no século XXI.

Segundo o Relatório, existe atualmente uma discrepância entre as condições econômicas dos países desenvolvidos e as dos países em desenvolvimento. Os motivos dessa divergência não são explicados pelos autores do documento, porém uma série de soluções é recomendada. A primeira sugestão proposta é a reforma da educação nos países em desvantagem econômica. Um dos fatores que permitem a condição de pobreza dessas nações é a falta de investimento na educação, pois, sem indivíduos preparados para o mercado de trabalho, as chances em se obter um emprego ${ }^{3}$ são reduzidas. Outra proposta do Banco Mundial para esses países é realizar uma reforma que se adapte com as necessidades da economia capitalista contemporânea. Os processos produtivos atualmente exigem um perfil de profissional distinto ao do operário da década de 1970, que necessitava possuir conhecimentos especializados sobre determinada 
atividade. Hoje, a formação profissional fundamental é aquela flexível, capaz de realizar diversas funções ao mesmo tempo, que exige conhecimentos gerais, ou seja, que permita a flexibilidade do indivíduo para diversos tipos de trabalho e amplie sua capacidade de empregabilidade.

As características do novo perfil profissional são denominadas pelos relatores do documento como aprendizagens para o século XXI, as quais, resumidamente, constituem os quatro pilares da educação: aprender a conhecer, aprender a fazer, aprender a viver e aprender a ser.

Aprender a conhecer, combinando uma cultura geral, suficientemente vasta, com a possibilidade de trabalhar em profundidade um pequeno número de matérias. O que também significa: aprender a aprender, para beneficiar-se das oportunidades oferecidas pela educação ao longo de toda a vida. Aprender a fazer, a fim de adquirir, não somente uma qualificação profissional, mas de uma maneira mais ampla, competências que tornem a pessoa apta a enfrentar numerosas situações e a trabalhar em equipe. Mas também aprender a fazer, no âmbito das diversas experiências sociais ou de trabalho que se oferecem aos jovens e adolescentes, quer espontaneamente, fruto do contexto local ou nacional, quer formalmente, graças ao desenvolvimento do ensino alternado com o trabalho. Aprender a viver juntos, desenvolvendo a compreensão do outro e a percepção das interdependências - realizar projetos comuns e preparar-se para gerir conflitos - no respeito pelos valores do pluralismo, da compreensão mútua e da paz. Aprender a ser, para melhor desenvolver a sua personalidade e estar à altura de agir cada vez com maior capacidade de autonomia, de discernimento e de responsabilidade pessoal. Para isso, não negligenciar na educação nenhuma das potencialidades de cada indivíduo: memória, raciocínio, sentido estético, capacidades físicas, aptidão para comunicar-se. (DELORS, 2001, p. 90)

Todas as aprendizagens citadas pelos relatores fazem referência ao novo comportamento que o trabalhador atualmente necessita desenvolver. Como afirmamos anteriormente, elas permitem que o sujeito, que aspira vender sua força de trabalho, tenha maiores chances (o que não significa garantia) de ser empregado, caso haja alguma vaga no mercado de trabalho.

Os autores dos Parâmetros Curriculares Nacionais do Ensino Médio adotam, com poucas alterações, os ensinamentos dos quatro pilares propostos pelo Relatório da Unesco e, por meio da organização curricular, as disseminam nos seguintes temas: o ensino das disciplinas em áreas específicas, a interdisciplinaridade, a estética da sensibilidade, a ética da identidade e a contextualização.

O conceito de trabalho nos PCN do ensino médio, por pretender atender às adaptações da economia contemporânea, assume um significado 
de dispêndio de força de trabalho designada à produção, pois "o trabalho é um contexto importante das Ciências Humanas, visando a compreendê-lo enquanto produção de riqueza e forma de interação do ser humano com a natureza e o mundo social" (BRASIL, 1999, p. 79). A categoria trabalho, diferente da interpretação marxiana, é avaliada como uma atividade que produz riqueza e interação entre os homens; porém, para Marx, o trabalho não é simplesmente uma interação entre os homens e a produção de riqueza (mercadorias que exprimem valor de troca), mas a atividade vital humana, inerente à sobrevivência, e aperfeiçoada ao longo do processo histórico por meio da relação entre os homens e seu intercâmbio com a natureza. A esse respeito, o autor acrescenta:

O trabalho, como criador de valores de uso, como trabalho útil é indispensável à existência do homem - quaisquer que sejam as formas de sociedade -, é necessidade natural e eterna de efetivar o intercâmbio material entre o homem e a natureza e, portanto, de manter a vida humana. (MARX, 2003, p. 65)

Marx conceitua a categoria trabalho enquanto a atividade que dá origem às características humanas, pois o processo de humanização não é intrínseco ao processo de hominização, isso é, o fato de um indivíduo pertencer à espécie Homo sapiens não lhe garante possuir comportamentos humanos, realizar trabalho, ser social, universal etc., se não houver a relação entre os indivíduos, e desses com a natureza, para desenvolver esse processo.

Dessa forma, analisamos que, nos PCN do ensino médio, a categoria trabalho não assume o significado que Marx propôs (no sentido original de definição dessa categoria) de reprodução da vida humana, mas o de produção de riquezas, por ser o conceito que o modo de produção capitalista (a forma dominante de formação econômica atual) e da classe que a representa (a burguesia) estabelece para os homens. O capitalismo permite que a capacidade de trabalho torne-se uma mercadoria, pela compra e venda da força de trabalho entre os homens, assim como o trabalho assume a função de produtor de mercadorias e de mais-valia, em prol da expansão incontrolável do capital.

Como citamos na primeira seção, o método dominante para produzir valor, após a década de 1970, é o processo toyotista. Esse método, que permite controlar a produção conforme a demanda da clientela, é também o método adequado às necessidades dos gigantescos investimentos do capital financeiro e de especulações, que exigem sempre a produção de novas mercadorias, a precoce autodestruição de si mesmas e a espoliação do trabalho que seja capaz de capturar a subjetividade dos trabalhadores (ALVES, 2000, p. 40-63). 
Dentre as características gerais do processo de produção toyotista, existem as transformações das relações organizacionais: a racionalização do trabalho, a automação/autoativação, o operário polivalente (realiza diversas tarefas na produção, faz reparos nas máquinas, oferece sugestões à empresa), a desespecialização do trabalhador, o sistema just-in-time e kanban. Há, ainda, as transformações institucionais: trabalhadores engajados à promoção, a emulação pelo bônus à produtividade ou à participação nos lucros e resultados, o comprometimento no trabalho em equipe, o empregado proativo ao desenvolvimento da empresa, o patrão de si mesmo e do trabalho dos seus colegas etc. (ALVES, 2000, p. 43-55-58).

Esses atributos do toyotismo são encontrados em cada empresa e setor produtivo, conforme as particularidades e necessidades de cada trabalhador. Porém, para a formação do educando para um mercado de trabalho que exige esse perfil de profissional, é necessário que todas as características, sem exceção, sejam prioridade da educação escolar. No Brasil, uma vez que o ensino médio é a etapa final do ensino básico, é responsabilidade dessa fase transmitir as denominadas competências e habilidades para o trabalho.

Nos Parâmetros Curriculares Nacionais do Ensino Médio, as novas aprendizagens para o mundo do trabalho no século XXI são destacadas, e os motivos de sua inserção nessa etapa da educação são justificados pela

consolidação do Estado democrático; as novas tecnologias e as mudanças na produção de bens, serviços e conhecimento exigem que a escola possibilite aos alunos integrarem-se ao mundo do trabalho contemporâneo nas dimensões fundamentais da cidadania e do trabalho. [...] A facilidade de acessar, selecionar e processar informações está permitindo descobrir novas fronteiras do conhecimento, nas quais esse se revela cada vez mais integrado. Integradas são também as competências e habilidades requeridas por uma organização da produção na qual criatividade, autonomia e capacidade de solucionar problemas serão cada vez mais importantes, comparadas à repetição de tarefas rotineiras. E mais do que nunca, há um forte anseio de inclusão e de integração sociais como antídoto à ameaça de fragmentação e segmentação. [...] Com essa leitura, a formação básica a ser buscada no ensino médio realizar-se-á mais pela constituição de competências, habilidades e disposições de condutas do que pela quantidade de informação. Aprender a aprender e a pensar, a relacionar o conhecimento com dados da experiência cotidiana, a dar significado ao aprendido e a captar o significado do mundo, a fazer a ponte entre teoria e prática, a fundamentar a crítica, a argumentar com base em fatos, a lidar com o sentimento que a aprendizagem desperta. (BRASIL, 1999, p. 13-71-87) 
Assim, os dois eixos centrais da organização curricular do ensino médio, necessários para atender aos imperativos da produção contemporânea, são o trabalho e a cidadania. Entretanto, a cidadania assume as mesmas exigências dos interesses do capital e do mercado de trabalho, por ser a eles agregada. Nos PCN do ensino médio, a cidadania traduz um caráter humanista, capaz de proporcionar a mobilização dos jovens para um mundo melhor, a melhoria da vida entre os homens e das nações de modo geral (possível pelo avanço econômico e o respeito aos direitos e deveres do Estado). No documento, os autores a denominam como a política da igualdade, ou seja, "o respeito ao bem comum com protagonismo [...] as condutas de participação e solidariedade, respeito e senso de responsabilidade, pelo outro e pelo público" (BRASIL, 1999, p. 77).

Subsumidos aos interesses das"mudanças nas formas de conviver, de exercer a cidadania e de organizar o trabalho, impostas pela nova geografia política do planeta, pela globalização econômica e pela revolução tecnológica" (BRASIL, 1999, p. 71), outros temas são contemplados na nova organização curricular dos PCN, por meio do ensino pelas áreas. Nessa nova organização da aprendizagem, o foco é promover uma concepção de ensino que aproxime as compreensões de mundo físico e natural, de modo que o aluno seja capaz de desenvolver estratégias de solução de problemas (BRASIL, 1999), isso é, habilidades que (como citamos acima) são essenciais para o trabalhador polivalente, o qual trabalha em equipe e necessita solucionar quaisquer problemas urgentes que alterem o desenvolvimento adequado da produção.

Como apoio ao ensino por áreas (Ciências Humanas e suas tecnologias; Ciências da Natureza e Matemática e suas tecnologias; Linguagens, códigos e suas tecnologias), é preciso que os educadores do ensino médio realizem a interdisciplinaridade dos conhecimentos e, principalmente, sua contextualização. A partir dessas duas intervenções, os educandos serão capazes de "recorrer a um saber diretamente útil e utilizável para responder às questões e aos problemas sociais contemporâneos" (BRASIL, 1999, p. 93). Entende-se isso, no caso da realidade do mercado de trabalho atual, como a utilização do saber escolar para se adotarem comportamentos que correspondam ao perfil de trabalhador que o mercado almeja, estando preparado para se adaptar a todas as adversidades que possam surgir.

A estética da sensibilidade também permite aproximar os conhecimentos da prática escolar àqueles do mundo do trabalho. Sua proposta é estimular a criatividade, o espírito inventivo, a curiosidade pelo inusitado, a busca pelo aprimoramento permanente, assim como a constituição de identidades prontas a suportar a inquietação, conviver com o incerto, o imprevisível (BRASIL, 1999). Ou seja, comportamentos que condizem com o 
perfil de trabalhador atual, capaz de envolver a sua subjetividade aos interesses da empresa, ao oferecer a sua criatividade às melhorias da corporação e, consequentemente, à sua promoção ou gratificação.

Por fim, destacamos, ainda, a importância que os autores dos PCN do ensino médio revelam como a principal aprendizagem permitida pela denominada ética da identidade: a autonomia. A autonomia assim como a formação de uma identidade capaz de suportar as incertezas do mercado de trabalho contemporâneo são comportamentos essenciais para os jovens, em um período cujo capitalismo os submete, cada vez mais, a condições precárias de trabalho e justifica sua não inserção no mercado pela falta de protagonismo de alguns indivíduos. Portanto, a autonomia tem a função de desenvolver nos educandos três competências: autonomia para a realização dos seus estudos, para o protagonismo de sua vida e para ser um trabalhador criativo, capaz de sugerir novas ideias e solucionar problemas no ambiente de trabalho.

Nesta seção, apresentamos a conceituação da categoria trabalho nos Parâmetros Curriculares Nacionais do Ensino Médio, as justificativas dos autores do documento para elaborar uma proposta de formação para o trabalho e a cidadania, quais são as principais exigências que o método de produção toyotista exige do profissional no século XXI e de que modo é possível transferir para as atividades escolares essas necessidades da esfera produtiva.

Na próxima seção, nosso objetivo é demonstrar que a preparação para o trabalho que os PCN do ensino médio buscam reproduzir nas escolas brasileiras destina-se a um mercado de trabalho hostil e precário, que afasta não apenas os jovens, mas muitos homens e mulheres, das condições mínimas de sobrevivência que um salário mínimo pode oferecer.

\section{A PRECARIZAÇÃO DO MUNDO DO TRABALHO}

As medidas de flexibilização na organização da produção e na contratação dos funcionários - que a empresa Toyota iniciou na década de 1950 e 1960 - foram, posteriormente, instauradas nos setores industriais e de serviços do mundo todo. Provocaram o acirramento do processo de precarização no trabalho que reflete para a classe trabalhadora contemporânea três fenômenos: a desconstrução da coesão da classe trabalhadora, o aumento da exploração dos assalariados e o individualismo exacerbado. Segundo Alves, o

processo de precarização do trabalho é o processo de diluição [ou supressão] dos obstáculos constituídos pela luta de classe à voracidade do capital no decorrer do século XX. É a explicitação da precariedade como condição 
ontológica da força de trabalho como mercadoria. A precarização possui um sentido de perda de direitos acumulados no decorrer de anos pelas mais diversas categorias de assalariados. A precarização é síntese concreta da luta de classes e da correlação de forças políticas entre capital e trabalho. É o conteúdo do Estado político da decadência histórica do capital. (ALVES, 2007, p. 114-115)

A atual precarização do trabalho é sintetizada, por Alves (2000), como a resposta do capital para se recuperar da crise da década de 1970 e dos direitos conquistados pelos trabalhadores dos países centrais naquele período. Para o autor, as medidas de flexibilização são inerentes à lógica do capital que busca, após determinados períodos de crises, recuperar a produção de lucros por meio da crescente exploração do trabalho (mais valia relativa). Entretanto, a recente estratégia de flexibilização apresentou um diferencial que foi a mundialização do capital, isso é, a propagação de investimentos financeiros em países do mundo todo e as medidas de flexibilização seguindo a expansão do capital financeiro por todos os territórios por onde se alastrava.

A flexibilização do trabalho é apontada, nos Parâmetros Curriculares Nacionais do Ensino Médio, como um importante requisito para a empregabilidade do jovem e como um dos grandes desafios do mundo e do mercado de trabalho no século XXI. No entanto, o que o documento não menciona são os verdadeiros motivos para que o modelo das competências - exigido pelo currículo do ensino médio - esteja associado à preparação para o mercado de trabalho. As justificativas apresentadas pelos autores do documento para o desemprego crescente são "as inovações tecnológicas, como a informatização e a robótica, e a busca de maior precisão produtiva e de qualidade homogênea que tem concorrido para acentuar o emprego" (BRASIL, 1999, p. 25). Essas justificativas amenizam os reais motivos que reestruturaram o modelo de produção após a década de 1970: crises diversas, expansão do capital especulativo, queda na taxa de lucro na produção industrial etc..

O modelo de competências estabelecido nos dias atuais é aquele organizado para atender todos os tipos de trabalho, isso é, formar jovens aptos para realizar qualquer trabalho que o mercado possa oferecer. Nesse caso, a profissionalização perde seu valor como qualificação, pois conhecer apenas uma atividade de trabalho é limitar sua disponibilidade enquanto um trabalhador empregável. Uma profissão específica, a ser exercida pelo mesmo trabalhador por trinta longos anos, pertence ao modelo de organização fabril fordista/taylorista das décadas de 1960/1970 e que se associava, por exemplo, à formação de sindicatos representativos de uma categoria exclusiva de profissionais. 
Atualmente, a formação, participação e atuação de sindicatos são precárias e escassas. Além dos ataques morais que sofreram pelas empresas para o seu enfraquecimento, as estratégias de precarização do trabalho na contratação - participação em lucros e rendimentos (PLR), terceirização, contratação parcial, temporária, trabalho autônomo, em domicílio etc. - e as estratégias institucionais para a competitividade na empresa e no mercado de trabalho, de modo geral, foram fundamentais para desmantelar a organização dos trabalhadores. De acordo com os autores dos PCN, o mercado de trabalho apresenta-se cada vez mais insuficiente para empregar a população, portanto, possuir as competências básicas para todos os tipos de trabalho é fundamental para se aumentar a chance de empregabilidade de cada indivíduo. Afinal, as aspirações por maior tempo de escolaridade"não decorre apenas da urbanização e modernização do crescimento econômico, mas também de uma crescente valorização de educação como estratégia de melhoria de vida e empregabilidade" (BRASIL, 1999, p. 64).

Dessa forma, desenvolver o protagonismo juvenil - isso é, "a formação da pessoa, de maneira a desenvolver valores e competências necessárias à integração de seu projeto individual ao projeto da sociedade em que se situa" (BRASIL, 1999, p. 22) - é fundamental para formar o jovem que irá se debater com um mercado de trabalho estreito e seletivo. De acordo com Alves (2000), além de precário, esse mercado promove os trabalhadores à situação de subproletariados nas seguintes condições: os trabalhos são realizados em tempo parcial, informal ou em domicílio; a jornada de trabalho e a produtividade são elevadas; os salários são baixos e a subjetividade do trabalhador (que no fordismo não era capturada) passa a ser subordinada aos interesses do capital.

Segundo o currículo para o ensino médio, indivíduos preparados e suscetíveis a adaptações, capazes de sustentar o sistema capitalista na sua forma atual constituem o perfil idealizado para os jovens brasileiros durante o governo de Fernando Henrique Cardoso e estendido, até então, nos governos posteriores. Não obstante os ideólogos da classe dominante afirmarem que o modelo de produção toyotista permite maior participação dos operários nos planejamentos e execução do trabalho, nas decisões e solução de problemas, entre outros, há uma farsa sutil e ludibriante. Os trabalhadores assumem decisões limitadas tão somente à sua atividade no processo de trabalho, segregadas do processo total de produção de mercadorias, e limitadas às cobranças e exigências da diretoria da empresa (o dono da empresa apesar de oculto fisicamente mantém o domínio dos interesses de lucros). Permanecem sendo apenas trabalhadores assalariados, a despeito da participação nos lucros e rendimentos (PLR). Segundo Marx, a alienação dos trabalhadores 
inerente ao processo de produção capitalista não é eliminada, de forma que o trabalhador mantém-se estranhado de sua própria produção, isso é, da mercadoria produzida.

O trabalho mesmo se torna o objeto, do qual o trabalhador só pode se apossar com os maiores esforços e com as mais extraordinárias interrupções. A apropriação do objeto tanto aparece como estranhamento que quanto mais objetos o trabalhador produz, tanto menos pode possuir e tanto mais fica sob o domínio do seu produto, do capital. (MARX, 2004, p. 81)

O trabalhador, além de estranhado do produto que ele mesmo produziu, é apartado, após o expediente, do uso dos meios de produção utilizados nos processos de trabalho, como também tem o seu próprio trabalho estranhado, pois a sua atividade pertence a outro. A posse dos meios de produção permanece exclusiva ao capitalista, uma vez que a tomada de decisões, limitada no decorrer de uma produção fragmentada, não elimina a condição do trabalhador enquanto sujeito que não possui os meios para produzir.

Em contraposição à afirmação dos PCN do ensino médio, de que o trabalhador contemporâneo é mais participativo e autônomo por ser capaz de planejar e interferir no desenvolvimento dos processos de produção, a única propriedade pertencente a esse indivíduo é sua força de trabalho, sua mercadoria exclusiva e vendável por meio de assalariamento a outro homem, o capitalista.

A externalidade do trabalho aparece para o trabalhador como se [o trabaIho] não fosse seu próprio, mas de um outro, como se [o trabalho] não lhe pertencesse, como se ele no trabalho não pertencesse a si mesmo, mas a um outro. (MARX, 2004, p. 83)

Como citamos há pouco, aqueles que trabalham em uma fábrica, empresa ou no setor de serviços, que realizam atividades que se inserem no perfil do modelo toyotista (tanto nas relações de produção quanto na forma de contratação e remuneração) não estão livres (mesmo que recebam um salário elevado) da condição de trabalhador assalariado. Essa situação, de acordo com Marx, perpetua a relação de poder entre capitalista e trabalhador no modo de produção capitalista, uma vez que a posição de ambos será mantida. O primeiro é aquele que detém os meios de produção; e o segundo, o que detém a força de trabalho (vendida por um salário) que manterá a produção de lucros e a propriedade privada do capitalista (mais valia relativa e absoluta). Dessa forma, Marx equivale salário à propriedade privada. 
Salário é uma consequência imediata do trabalho estranhado, e o trabalho estranhado é a causa imediata da propriedade privada. [...] Reconhecemos que salário e propriedade privada são idênticos, pois o salário [cujo produto, o objeto do trabalho, paga o próprio trabalho] é somente uma consequência necessária do estranhamento do trabalho, assim como no salário também o trabalho aparece não como fim em si, mas como o servidor do salário. Salário é a consequência imediata do trabalho estranhado, é a causa imediata da propriedade privada. (MARX, 2004, p. 88)

Portanto, toda a organização curricular dos PCN do ensino médio destaca que - para melhorar a vida dos indivíduos, sua empregabilidade e sua condição financeira, e para reduzir a pobreza e auxiliar o desenvolvimento econômico do país - é importante a formação dos educandos para a esfera produtiva. Contudo, isso não passa de um engodo para a classe trabalhadora e sua prole permanecerem em sua condição enquanto classe subordinada a uma organização econômica, política e social, voltada à produção e reprodução do capital. As estratégias de flexibilização nas relações de produção e contratação são a arma que os setores (dos serviços, indústria, empresas etc.) utilizaram para sustentar a criação de lucros e não um privilégio para os trabalhadores serem mais livres nos seus postos de trabalho.

Por fim, cabe destacarmos os dados de uma recente pesquisa do IPEA que revela a situação emergencial das oportunidades do mercado de trabalho para os jovens brasileiros. De acordo com $24 \%$ dos entrevistados desempregados, a justificativa para não se conseguir um emprego é a falta de qualificação e/ou experiência para se adequar a uma vaga.

No tocante aos desempregados, observa-se que nesse grupo estão especialmente sobrerrepresentados os jovens entre 18 e 29 anos: embora correspondam a apenas cerca de $30 \%$ da amostra, perfazem $54 \%$ dos desempregados. Esse dado está de acordo com o que é verificado nas pesquisas de emprego, evidenciando que o desemprego é particularmente concentrado entre os jovens. (IPEA, 2011, p. 11)

Dos entrevistados que justificaram estarem desempregos por falta de qualificação e/ou experiência, 28\% são jovens entre 18 e 29 anos. Entretanto, não podemos afirmar que o principal motivo do desemprego entre os jovens seja a falta de qualificação, pois os dados estão conjugados. Porém, o segundo item destacado pela causa do desemprego é a concorrência (17\%) entre os formados da mesma área.

Dessa forma, podemos afirmar que nem mesmo a qualificação (preparação para competir no mercado de trabalho), enfatizada repetidas 
vezes pelos autores dos $\mathrm{PCN}$ do ensino médio, é suficiente para imunizar os jovens brasileiros do estreito mercado de trabalho (precário) contemporâneo; afinal, $16 \%$ deles afirmam não conseguir emprego pelo excesso de formados que possuem a sua mesma qualificação.

\section{CONSIDERAÇÕES FINAIS}

Ao longo deste trabalho, buscamos demonstrar quais foram as principais transformações nas relações do mundo do trabalho, na economia e política mundial após a crise de 1970. Procuramos pontuar, também, de que forma essas mudanças influenciaram na reforma educacional brasileira nos anos 1990, especificamente na criação dos Parâmetros Curriculares Nacionais do Ensino Médio (PCNEM).

Observamos que a categoria trabalho, eixo central da organização curricular para o ensino médio, é aquela que condiz com a ideologia da classe dominante, a burguesia, representada pelas teorias de David Ricardo e, principalmente, Adam Smith, em que o trabalho é a atividade que cria riqueza. Porém, balizados pela crítica à economia política de Karl Marx, interpretamos que os objetivos da categoria trabalho e das demais adaptações às exigências para o mundo do trabalho - que os autores dos PCN do ensino médio afirmam serem essenciais para a empregabilidade na sociedade contemporânea - visam à função de reproduzir a lógica do modo de produção capitalista. Almejam manter o antagonismo de classes, o trabalho estranhado, a produção de lucros, o trabalho assalariado e precarizado e a produção de riqueza material enquanto valores de troca e não como valores de uso necessários para a reprodução da vida humana.

Assim, compreendemos - pelas palavras de Marx em que "os pensamentos da classe dominante são também, em todas as épocas, os pensamentos dominantes" (MARX; ENGELS, 1989, p. 47) - que a proposta dos autores dos PCN do ensino médio e do governo atuante naquele período tinha o objetivo unilateral de reproduzir os interesses da classe burguesa. Não houve qualquer preocupação em romper, por meio de uma proposta educacional contra-hegemônica, com a exploração dos homens e mulheres que constituem a classe trabalhadora e, principalmente, com a futura exploração dos jovens que compõem a escola pública brasileira.

Consideramos, também, que os criadores dos PCN, além de propor aos jovens brasileiros um ensino limitado em conformidade com as exigências do mundo do trabalho - o qual aparta os educandos dos conhecimentos historicamente acumulados que poderiam ser úteis para a compreensão dos fundamentos e para a luta contra a classe dominante e a lógica do 
modo de produção capitalista -, responsabilizam os jovens educandos pelas intempéries do seu destino, caso não sejam inseridos no mercado de trabalho.

A escola do ensino médio, abalizada pela proposta curricular dos PCN, assegura oferecer as aprendizagens necessárias para desenvolver a empregabilidade dos educandos; porém, o potencial do protagonismo juvenil e de qualificação após a educação básica é responsabilidade de cada indivíduo. Isso isenta a esfera pública das oportunidades de trabalho a que os jovens serão, ou não, submetidos ao longo de sua vida, ocultando as críticas de Marx em relação ao surgimento do exército industrial de reserva, inerente à acumulação do capital, no qual parte da classe trabalhadora é apartada de qualquer tipo de trabalho. Afinal, "a demanda de trabalho não é idêntica ao crescimento do capital, a oferta de trabalho não é idêntica ao crescimento da classe trabalhadora" (MARX, 1996, p. 270).

NATIONAL CURRICULUM PARAMETERS FOR SECONDARY EDUCATION: PREPARING FOR THE INSECURITY OF THE LABOR MARKET

ABSTRACT:The objective of this paper is to show how the category work is addressed in the National Curriculum Parameters for Secondary Education (PCNEM), as this category is considered the main plank for the formulation of curriculum reform in secondary education. In that document, there are two central planks, work and citizenship, but citizenship is aggregated and subjected to the new requirements of the labor market, which according to the document, was set up after the 1970s. According to the authors of the PCNEM, contemporary society underwent two major transformations in the 70s: the revolution of technology and of knowledge, which gave rise to new demands in the production process, labor market and social relations. Based on these Education Ministry justifications for the reform of Brazilian secondary education, the goal of this article is to analyze how work is defined in the document, how curriculum organization at secondary school level has adapted to the new trends and what are these new demands of the labor market to which the document intends to adapt. For this analysis, the categories work, alienated work and job insecurity are used.

KEYWORDS: National Curriculum Parameters for Secondary Education. Labor. Citizenship. Productive Restructuring. Job insecurity.

LOS PARÁMETROS CURRICULARES NACIONALES DE LA ENSEÑANZA MEDIA: LA PREPARACIÓN PARA EL PRECARIO MUNDO DEL TRABAJO

RESUMEN: El objetivo de este artículo es presentar de qué forma la categoría trabajo es abordada en los Parámetros Curriculares Nacionales de la Enseñanza Media (PCNEM), puesto que, esta categoría es considerada el eje principal para la formulación de la reforma curricular de ese nivel de enseñanaza. En este documento, hay dos ejes 
centrales, el trabajo y la ciudadanía, pero, la ciudadanía es agregada y subordinada a las nuevas exigencias del mundo del trabajo que, de acuerdo con el documento, fue constituído después de la década de 1970. Según los autores de los PCNs de la enseñanza media, la sociedad contemporánea sufrió dos grandes transformaciones en los años 70: la revolución tecnológica y del conocimiento, las cuales originaron las nuevas exigencias del proceso productivo, del mercado de trabajo y de las relaciones sociales. A partir de esas justificativas del MEC para la reforma de la enseñanza media brasileña, nuestro objetivo en este artículo es averiguar de qué forma la categoría trabajo es conceptuada en el documento, cómo la organización curricular de la enseñanza media se adaptó a las nuevas tendencias y cuáles son esas nuevas exigencias del mundo del trabajo a las que el documento pretende adaptarse. Para ese análisis, utilizamos las categorías: trabajo, trabajo estraño y la precarización del trabajo.

Palabras claves: Parámetros Curriculares Nacionales de la Enseñanza Media. Trabajo. Ciudadanía. Reestructuración Productiva. Precarización del Trabajo.

\section{NOTAS}

1. Segundo Gounet (1999, p. 26-27), o método de produção toyotista pode ser resumido em seis pontos: 1 ) a produção dos veículos é puxada pela demanda, portanto não há estoques; 2 ) a empresa decompõe o trabalho em quatro operações (transporte, produção propriamente dita, estocagem e controle de qualidade) e na constante redução de espaço entre essas operações para combater o desperdício; 3 ) o desenvolvimento do trabalhador polivante e flexível; 4) a instalação do sistema kanban e just-in-time; 5) a preparação e antecipação das operações para reduzir o tempo de trabalho; 6) a contratação de operários terceirizados e a intensificação do trabalho.

2. Para Antunes, o processo produtivo taylorista-fordista "estruturou-se com base no trabalho parcelar e fragmentado, na decomposição de tarefas, que reduzia a ação operária a um conjunto repetitivo de atividades cuja somatória resultava no trabalho coletivo [...]. Era necessário também racionalizar ao máximo as operações realizadas pelos trabalhadores, combatendo o 'desperdício' na produção, reduzindo o tempo e aumentando o ritmo de trabalho, visando a intensificação das formas de exploração [...]. Esse processo produtivo caracterizou-se, portanto, pela mescla da produção em série fordista com o cronômetro taylorista, além de uma separação nítida entre elaboração e execução" (ANTUNES, 2005, p. 37).

3. A diferença entre as categorias trabalho e emprego é que enquanto a primeira incorpora qualquer tipo de atividade objetivada (remunerada ou não) em que há dispêndio intelectual e físico humano, o emprego refere-se, conforme Alves, a uma particularidade do operário moderno que é "apresentado como sujeito de direitos sociais e políticos"(ALVES, 1999, p. 118) como, por exemplo, o direito à seguridade social. 


\section{REFERÊNCIAS}

ALVES. G. Dimensões da globalização: o capital e suas contradições. Londrina: Práxis, 1999.

ALVES. G. O novo e (precário) mundo do trabalho: reestruturação produtiva e crise do sindicalismo. São Paulo: Boitempo, 2000.

ALVES. G. Dimensões da reestruturação produtiva: ensaios da sociologia do trabalho. Londrina: Práxis, 2007.

ANTUNES, R. Os sentidos do trabalho - Ensaio sobre a afirmação e a negação do trabalho. São Paulo: Boitempo, 2005.

BRASIL. Secretaria de Educação Média e Tecnológica. Parâmetros Curriculares Nacionais: ensino médio. Brasília: MEC/SEMTEC, 1999.

DELORS, J. et. al. Educação: um tesouro a descobrir. Relatório para a UNESCO da comissão internacional sobre educação para o século XXI. São Paulo: Cortez; Brasília: MEC/Unesco, 2001.

GOUNET, T. Fordismo e toyotismo na civilização do automóvel. São Paulo: Boitempo, 1999.

IPEA. Trabalho e renda: sistema de indicadores de percepção social. Disponível em: www.ipea.gov.br. Acesso em: 12 mar. 2011.

MARX, K.; ENGELS, F. A ideologia alemã. São Paulo: Martins Fontes, 1989.

MARX, K. Manuscritos econômicos - filosóficos. São Paulo: Boitempo, 2004.

MARX, K. O Capital: crítica da economia política. Livro I. Rio de Janeiro: Civilização Brasileira, 2003.

MARX, K. O Capital: crítica da economia política: Livro I. Tomo 2. São Paulo: Editora Nova Cultural, 1996.

MÉSZÁROS, I. A crise estrutural do capital. São Paulo: Boitempo, 2009.

PATRÍCIA REGINA PIOVEZAN: mestranda em Educação no Programa de Pós-Graduação na Universidade Estadual Paulista (UNESP). E-mail: patriciapiovezan8@hotmail.com

CANDIDO GIRALDEZ VIEITEZ: doutor e professor no Programa de Pós-Graduação em Educação da Universidade Estadual Paulista (UNESP) - Campus de Marília.

E-mail: vieitez@cebinet.com.br 